\title{
Trazer Marivaux até nós Os juramentos indiscretos, pelo Teatro dos Aloés
}

\section{João Carneiro}

dos Aloés / TNSJ,

2012 (Carla Chambel,

Sara Cipriano

e Nuno Nunes)

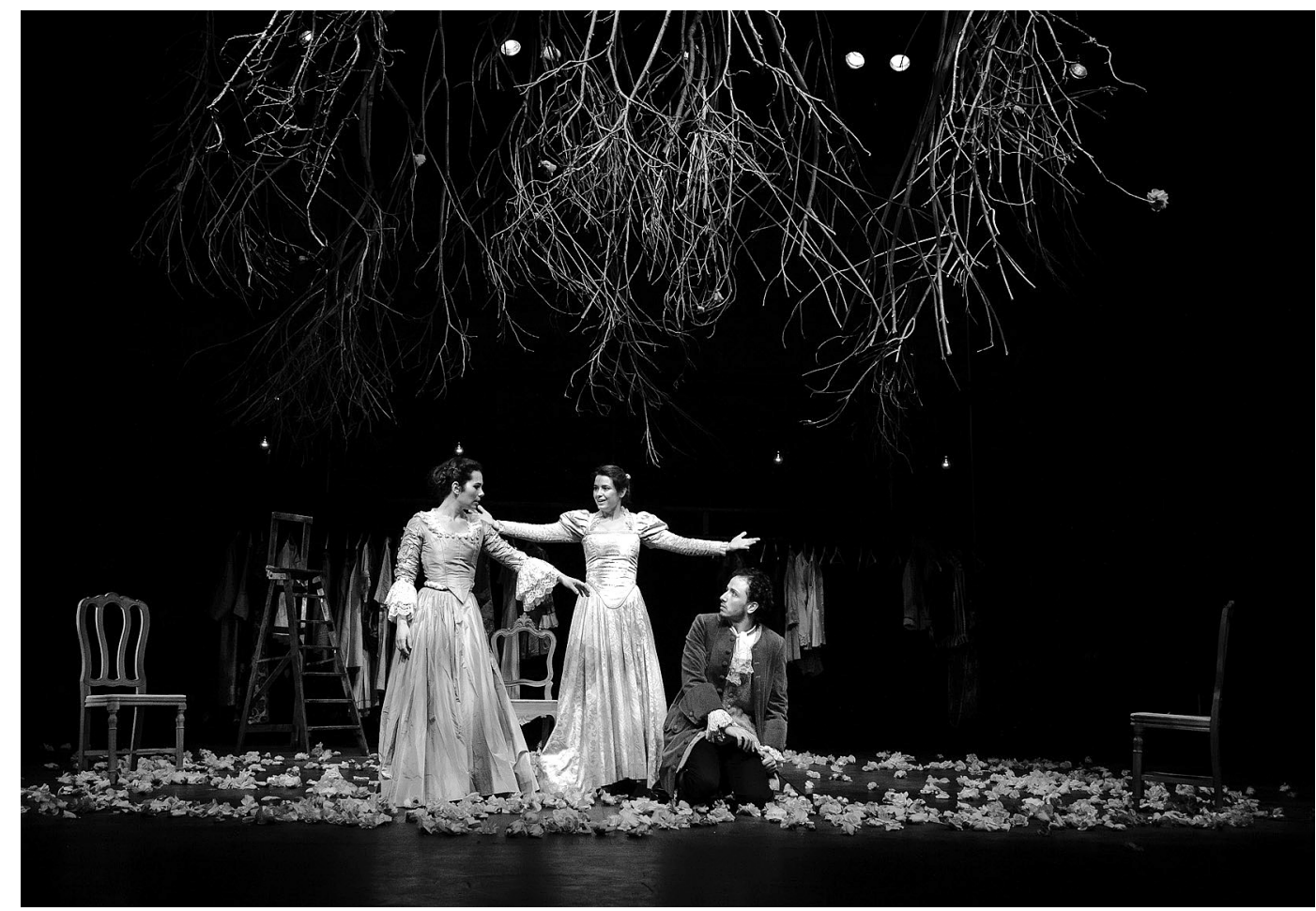

Tem sido notória e notável a presença de textos literários, nomeadamente os chamados grandes textos, na recente criação teatral portuguesa. Essa presença, se pode ser extensiva ao repertório estritamente dramático, ainda está longe de dar uma resposta ao desejo de uma real familiaridade do teatro português com esse mesmo repertório.

Os juramentos indiscretos, de Marivaux, do Teatro do Aloés (em co-produção com o Teatro Nacional São João) é por isso mesmo um marco importante na nossa vida teatral. Um autor conhecido de nome, mas longe de ser familiar do grande público; uma tradução exemplar (de Maria João Brilhante); um trabalho de actores refinado e inteligente (com Carla Chambel, Carlos Malvarez, Adriana Moniz, Jorge Silva, Nuno Nunes, Sara Cipriano e José Peixoto); um dispositivo cenográfico (de Marta Carreiras) totalmente adequado aos propósitos da peça e da encenação; e a dedicação sem par de José Peixoto, encenador do espectáculo e uma das almas do Teatro dos Aloés.

Um rapaz e uma rapariga estão destinados, pelos pais, a casar um com o outro. Não se conhecem. 0 rapaz e 


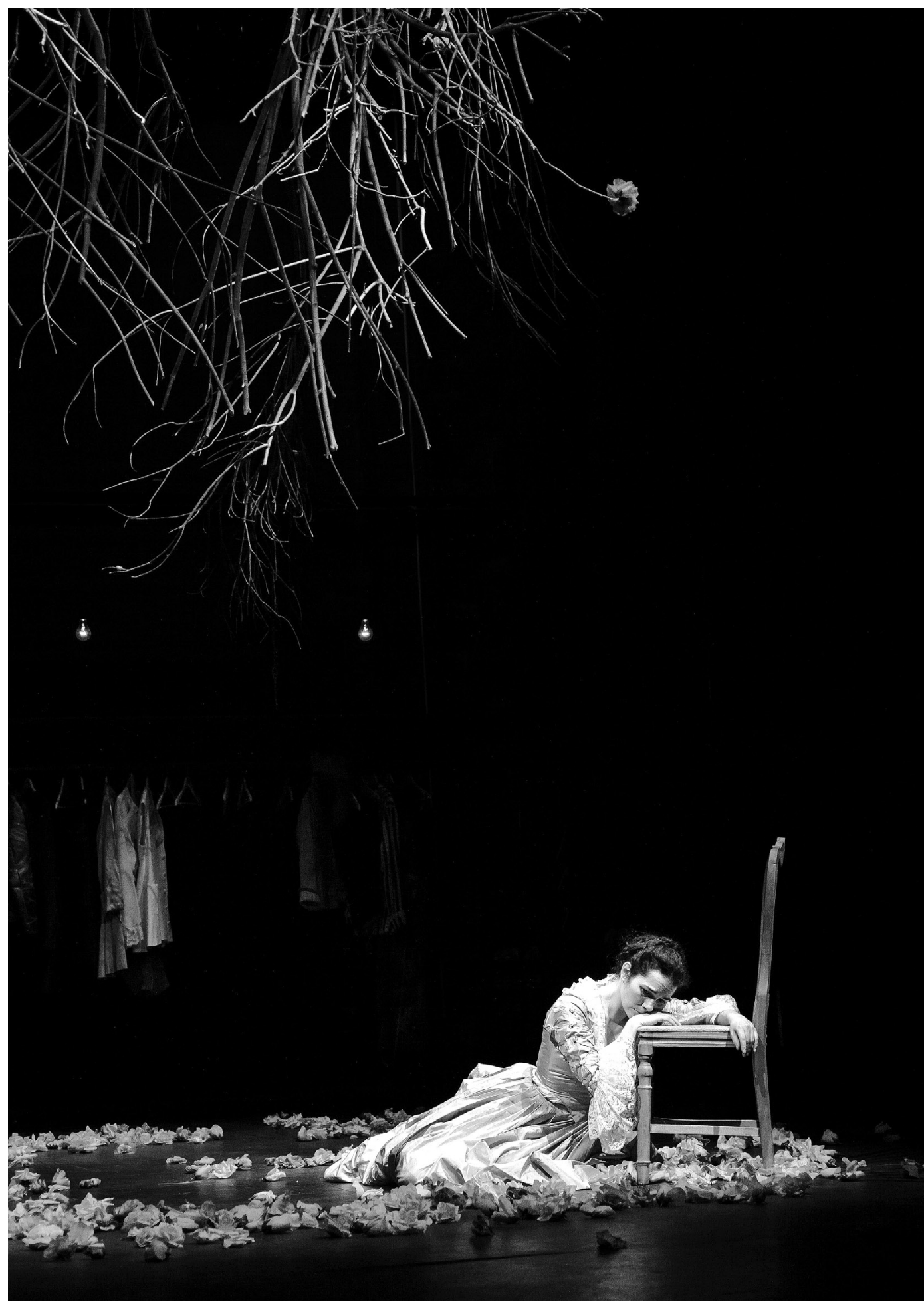

rapariga decidem também, cada um por seu lado, não casar senão com quem conheçam. Não querem casar por ser necessário ou imposto casar. Querem ser regidos, nas suas vidas, por aquele sentimento difícil de descrever e a que chamam amor. Querem, também, que isso signifique que as suas vidas são regidas por um muito especial critério de verdade, um critério em que verdade coincide com conhecimento, em que verdade, conhecimento e amor coincidem uns com os outros.

0 rapaz e a rapariga querem manter-se fiéis às suas decisões iniciais, mas, quando se conhecem, arrependem- se. Amam-se. Toda a peça vai ser uma tentativa de repor a verdade dos sentimentos, sem trair a verdade das decisões iniciais. 0 propósito parece impossivel. Como todos

percebem, na peça, o "coração troça das nossas decisões", coração e convenções nem sempre vão a par. Que fazer? Como fazer?

É um vasto e ambicioso projecto. É um projecto tão ambicioso que a sua escala, partindo de uma reflexão e de uma decisão estritamente individual, ambiciona estenderse a toda a humanidade, ambiciona poder criar a ponte entre o estritamente particular e o absolutamente universal. 
Os juramentos

indiscretos,

de Marivaux

enc. José Peixoto,

Teatro dos Aloés / TNS

2012

(> José Peixoto

e Jorge Silva;

$\checkmark$ Carla Chambe

e Nuno Lopes:

$\vee$ [em cima]

José Peixoto, Nuno Nunes,

Carla Chambel,

orge Silva, Sara Cipriano,

[em baixo]

Carlos Malvarez

e Adriana Moniz),

fot. João Tuna / TNSJ.
As personagens de Os juramentos indiscretos têm todas "almas ternas e doces", mesmo que pareça que uns são mais ternos e doces do que outros. Fazer prevalecer o coração sobre a decisão "de cabeça" vai ser uma tarefa árdua, porque é preciso que o coração não traia a razão. É preciso que o coração esteja do lado da verdade. É preciso que o coração esteja do lado da razão, ou que a razão do coração nunca seja uma traição. Como se consegue este milagre? Deixando agir o amor. Sabendo escutar uma espécie de voz interior que faz rimar amor com certeza. Estando seguro que a verdade está do nosso lado, ou nós do lado da verdade. Amor e moral são, assim, uma e a mesma coisa.

Por isso, quando se diz, por vezes, que Marivaux não se preocupa com a vida das sociedades, isso é totalmente falso. Indo ao coração dos homens e das mulheres, dos seres humanos, ele consegue chegar ao cerne daquilo que governa as sociedades, que são grupos de pessoas, de indivíduos.

Só falta uma coisa - a cereja em cima do bolo, para descer ao banal quotidiano. É o final feliz. Marivaux acredita que a felicidade é melhor do que a infelicidade, que o bem é melhor do que o mal. 0 final feliz é a sua maneira de propor um universo perfeito a um universo que é imperfeito, mas no qual a perfeição da felicidade é o que de melhor se pode desejar para o homem e para a humanidade. É isso o seu teatro, e é por isso que ele não fica ultrapassado; nunca ficará ultrapassado, pois dizer isso não tem sentido.

Fazer este teatro, mostrar estas obras, preferir estes objectos, é uma obstinação sem preço. Quando José Peixoto, com o Teatro dos Aloés, nos propõe um destes acontecimentos, está a dar corpo a tudo aquilo que tentei descrever, ou pelo menos referir, até agora, ao longo deste texto. E está a trazer Marivaux até nós, até hoje, sem que os séculos que separam a vida de Marivaux das nossas vidas sejam um qualquer tipo de obstáculo.
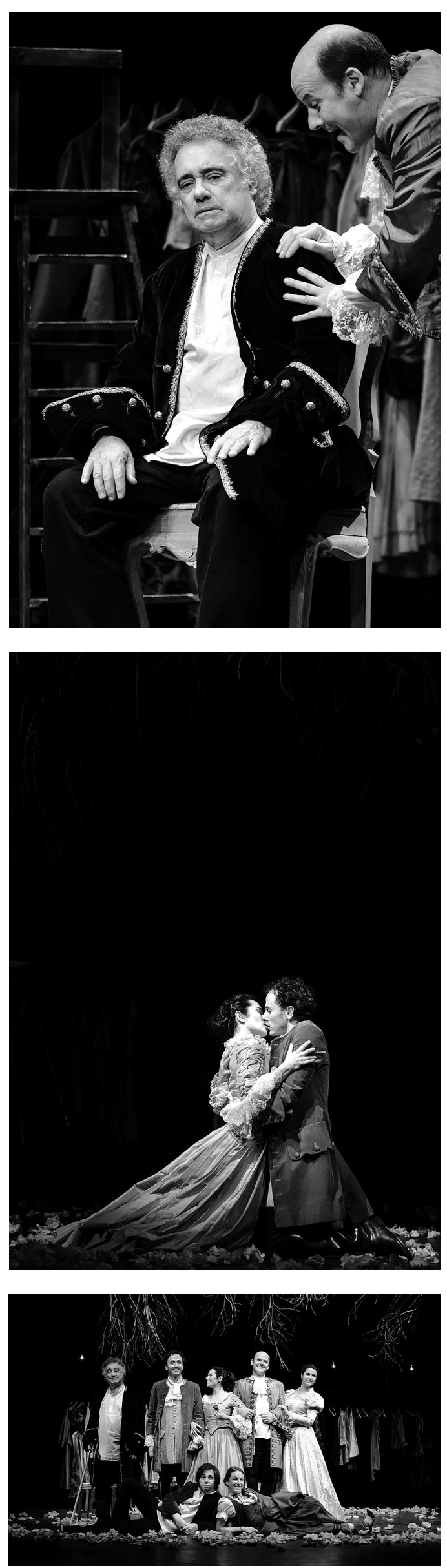